\title{
Analysis of the Relationship between Traditional Birth Attendant Service and the Risk of Hepatitis B Transmission among Pregnant Women at the Indonesian Rural Community
}

\author{
M. Nadjib Bustan ${ }^{1}$, Ansariadi ${ }^{2}$,Ermawati Syam ${ }^{3}$,Masyitha Muis ${ }^{4}$ \\ \{mnbustan@unm.ac.id ${ }^{1}$, ansariadi@gmail.com ${ }^{2}$, emma_survblk@yahoo.com ${ }^{3}$ \\ masyithamuis@yahoo.co.id $\left.{ }^{4}\right\}$
}

\begin{abstract}
Department of Statistics, Faculty of Mathematics and Natural Science, Makassar University, Indonesia ${ }^{1}$ Department of Epidemiology, Faculty of Public Health, Hasanuddin University, Indonesia ${ }^{2,3}$ Department of Occupational Health and Safety, Faculty of Public Health, Hasanuddin University, Indonesia $^{4}$
\end{abstract}

\begin{abstract}
Childbirth assistance with traditional birth attendant is carried out without regard to the sterilization factor so that transmission of the hepatitis virus can occur. This study aimed to determine the likelihood of Hepatitis B transmission in pregnant women based on the history of delivery assistance by traditional birth attendants. The study design was a case-control study of 120 cases of positive HVBsAg pregnant women and 120 negative HVBsAg pregnant women controls from the HVB screening program of Health Centers throughout Bulukumba District, Indonesia. Binary logistic regression analysis was carried out to determine the magnitude of the relationship between risk factors for labor history by TBA and HVB infection. Bivariate logistic regression model found that pregnant women with a history of childbirth by TBA have a risk of transmitting HVB 1.8 times greater (Odds Ratio = 1.78; 95\% CI $1.07-2.98$ ) compared with those who do not have a history of labor for TBA. The multivariate logistic regression model showed that pregnant women who received TBA help who had a history of blood transfusion and a history of surgical treatment had a risk of contracting HVB by 1.8 times greater than those delivered by midwives or other skilled health workers (Odds Ratio $=1.882 ; 95 \%$ CI 1,078 - 3,080). TBA services that pay less attention to sterilization in childbirth services have a risk of HVB transmission, especially if it occurs in those who have a history of blood transfusion and surgery.
\end{abstract}

Keywords: Traditional birth attendant, Hepatitis B, binary logistic regression

\section{Introduction}

Traditional birth attendants still play a role in helping deliveries of pregnant women in rural areas [1]. Childbirth assistance is done by not paying attention to the sterilization factor to allow transmission of the vial. [2] This study aimed to determine the likelihood of the Hepatitis B virus (HVB) transmission in pregnant women based on the history of delivery assistance by traditional birth attendants (TBA).

Hepatitis is a global disease that affects one-third of the world's population with HVB. [3] The prevalence of HVB in the Southeast Asian region is quite high $(2 \%)$ where Indonesia is 
the second highest after Myanmar. It is estimated that Indonesia's prevalence is between 2.5$10 \% .2$ HVB infection can be a further complication of cirrhosis and liver cancer, with the result of the death of 1.4 million people per year [3].

HVB prevalence data in Indonesia showed 2.76\%, and in South Sulawesi, it was 4\% [4], and in Bulukumba as a rural area was 2.93\%. [5] HVB is a contagious viral disease, 50-100 times more infectious than HIV / AIDS. The modes of transmission can be perinatal, parenteral, and sexual transmission/drug injections. [6] $42.86 \%$ of pregnant women transmit HVB to their babies, [7] and for $90 \%$ of infants infected with HVB in the first year of life [3].

Determinant HVB includes various factors consisting of genetic factors, service environment, lifestyle, health service factors, environmental factors, and lifestyle / family factors [8] Transmission can occur through perinatal transmission, horizontal transmission with blood transfusion, sexual, parental / needle injections, medical / dental care measures [9], [10].

To analyze the magnitude of the effect of TBA service on the possibility of contracting HVB by controlling the effect of parity factors, history of blood transfusion and history of surgical treatment was carried out using a binary logistic regression model [11].

\section{Materials and Methods}

The design of this study was a case-control study consisting of 120 cases of positive HVBsAg pregnant women and 120 controls of negative HVBsAg pregnant women in the HVB screening program from all of Health Centers in Bulukumba Regency, Indonesia.

The study aimed to determine the magnitude of the effect of TBA services on the possibility of HVB events, by controlling parity factors, blood transfusion and history of surgical treatment. For this reason, binary logistic regression analysis was conducted to determine the magnitude of the relationship between risk factors for labor history by TBA and HVB infection.

Binary logistic regression analysis was used to explain the relationship between response variables in the case of HVB in the form of dichotomic or binary data (case vs. control) with independent variables in the form of categorical data (parity, history of blood transfusion, and surgical history). The model used in binary logistic regression is:

$$
\log (p / 1-p)=\beta 0+\beta 1 X 1+\beta 2 X 2+\ldots .+\beta k X k
$$

Where $\mathrm{p}$ is the possibility that $\mathrm{Y}=1$, and $\mathrm{X} 1, \mathrm{X} 2, \mathrm{X} 3$ are independent variables in the form of parity, history of blood transfusion, and surgical history.

The steps for using binary logistic regression analysis are (1) Model Significance Test, using test statistics where Lo $=$ Maximum Likelihood of the

value of each predictor. The odds (odds) of an event are defined as the probability of the results that arise which are divided by the probability of an event not occurring. In general, the odds ratio (odds ratios) is a set of opportunities divided by other opportunities. The odds ratio for predictors is defined as the relative number where the probability of yield increases (odds ratio $>1$ ) or down (odds ratio $<1$ ) when the predictor variable value increases by 1 unit [12].

\section{Results}


Binary logistic regression forms a predictor or response variable $(\log (\mathrm{p} /(1-\mathrm{p}))$ which is a linear combination of independent variables. This predictor variable value is then transformed into a probability with the logit function.

The binary logistic regression model of TBA factor with the risk of HVB found that pregnant women with a history of labor by TBA had a risk of transmitting HVB to the expectant mothers of infants was 1.8 times greater (Odds Ratio $==1.78$; 95\% CI $1.07-2.98$ ) compared to those who did not have a history of labor for TBA.

As a result of the analysis of the binary logistic regression model the determinant factors of HVB obtain the following models:

$\mathrm{Y}=-3.5008+0,600$ (TBA service) +0.805 (history of blood transfusion) +0.568 (surgical history).

The value of $\operatorname{expB} 0.600$ service means Odds Ratio $=1.822$. This Odds Ratio value of 1,822 means that the magnitude of the influence of shaman services on the risk of contracting HVB is almost two times higher than that of those receiving services other than TBA.

Table 1. Logistic Regression Model Effect of TBA Services on HVB Risk

\begin{tabular}{|c|c|c|c|c|c|c|c|c|}
\hline Determinant Factors & $\mathrm{B}$ & S.E. & Wald & $\mathrm{df}$ & Sig. & $\operatorname{Exp}(B)$ & \multicolumn{2}{|c|}{$95 \%$ C.I.for $\operatorname{Exp}(\mathrm{B})$} \\
\hline & & & & & & & Lower & Upper \\
\hline TBA service & .600 & .268 & 5.017 & 1 & .025 & 1.822 & 1.078 & 3.080 \\
\hline Blood transfusion & .805 & .456 & 3.125 & 1 & .077 & 2.237 & .916 & 5.464 \\
\hline History of surgery & .568 & .425 & 1.791 & 1 & .181 & 1.765 & .768 & 4.056 \\
\hline Constant & -3.508 & 1.084 & 10.468 & 1 & .001 & .030 & & \\
\hline
\end{tabular}

The best binary logistic regression model is the effect of TBA along with a factor in the history of blood transfusion and a history of surgical treatment with Odds Ratio $=1.82(95 \%$ CI 1.08-3.08). This means that pregnant women who get TBA help have a 1.8 times greater risk of contracting HVB after being controlled by transfusion factors and surgical history.

\section{Discussion}

HVB virus infection is still a fairly prevalent disease, or the frequency of occurrence is still high in various countries, including Indonesia. Prevalence of HBV infection among Iranian pregnant women was estimated at $1.2 \%$ [13]. The high prevalence of HVB was associated with HVB maternal levels. Review of the epidemiology of HVB risk factors stated the importance of TBA service factors as one of the determinant factors of HVB incidence [8].

Various studies have found the importance of TBA service factors as HVB determinants. A cross-sectional study was carried out in Iraq,16, and Ethiopia [14] and case-control studies conducted in Palestine10 proved the importance of the role of TBA. Research on the tendency of the HVB area to show more HBV in rural areas than urban areas[15], [16]. In analyzing HVB risk factors, one of the analysis models that can be used is logistic regression [12], [17].

To overcome the high prevalence of HVB, it is advisable to take various preventive measures such as screening [6], [10] and vaccination [3]. Also, collaboration or skills training can be done to the TBA [18]. 


\section{Conclusion}

TBA services that pay less attention to sterilization in childbirth services have a risk of HVB transmission, especially if it occurs in those who have a history of blood transfusion and surgery. Therefore, it is expected to provide TBA personal hygiene training and tool sterilization in delivery assistance services to pregnant women by the local health office. Besides that, it is expected to increase vaccination efforts to decrease the incidence of HVB.

\section{References}

[1] Miller T, Smith H.: Establishing partnership with traditional birth attendants for improved maternal and newborn health. A review of factors influencing implementation. BMC Pregnancy Childbirth. Vol.19, pp. 365. (2017)

[2] World Health Organization, World Health Organization. Global Hepatitis Programme. Global hepatitis report, pp. 68. (2017)

[3] Andersson MI, Rajbhandari R, Kew MC, Vento S, Preiser W, Hoepelman AIM, et al.: Mother-tochild transmission of hepatitis B virus in sub-Saharan Africa. Time to act. Lancet Glob Heal. Vol. 3 , pp. 8-9. (2015)

[4] Bhat M, Ghali P, Deschenes M, Wong P.: Prevention and Management of Chronic Hepatitis B. Int J Prev Med. Vol. 5, pp. hal. (2014)

[5] Navabakhsh B, Mehrabi N, Estakhri A, Mohamadnejad M, Poustchi H.: Hepatitis B Virus Infection during Pregnancy. Transmission and Prevention. Middle East J Dig Dis. Vol. 3, pp. 92-102. (2011)

[6] Health Office SS.: Health Profile of Provinsi Sulawesi Selatan. (2014)

[7] Bulukumba DK.: Laporan Bulanan Rekapitulasi Ibu Hamil yang Melakukan Deteksi Dini Hepatitis B Tahun 2018. (2018)

[8] Lawal A S Danbuzu. Umar Musa.: A Geographic Epidemiological Review of Viral Hepatitis B. IOSR J Dent Med Sci. Vol.3. pp. 34-6. (2015)

[9] Nazzal Z, Sobuh I.: Risk factors of hepatitis B transmission in northern Palestine. A case - control study. BMC Res Notes. Vol. 28, pp. 190. (2014)

[10] Janahi EM.: Prevalence and risk factors of hepatitis B virus infection in Bahrain, 2000 through 2010. PLoS One. Vol. 9, pp.4-8 (2000)

[11] Hosmer DW, Lemeshow S, Sturdivant RX.: Applied logistic regression. pp 1-369. (tahun)

[12] Adjei IA, Karim R. An.: Application of Bootstrapping in Logistic Regression Model. OALib. Vol. 30, pp. 1-9. (2016)

[13] Moghaddasifar I, B. Lankarani K, Moosazadeh M, Afshari M, Malary M.: Prevalence of Hepatitis B Virus infection among Pregnant Women in Iran. A Systematic Review and Meta-analysis. Iran J Cancer Prev. Vol 9. pp. 1-9. (2016)

[14] Molla S, Munshea A, Nibret E.: Seroprevalence of hepatitis B surface antigen and anti HCV antibody and its associated risk factors among pregnant women attending maternity ward of Felege Hiwot Referral Hospital, northwest Ethiopia: a cross-sectional study. Virol J. Vol. 2, pp. 204. (2015)

[15] Mehmet D, Meliksah E, Serif Y, Gunay S, Tuncer O, Zeynep S.: Prevalence of hepatitis B infection in the southeastern region of Turkey: comparison of risk factors for HBV infection in rural and urban areas. Jpn J Infect Dis. Vol. 58. pp. 15-9. (2005)

[16] Bankole Henry Oladeinde RO, Mitsan Olley JA.: Hepatitis B and C Viral Infections among Pregnant Women in a Rural Community of Nigeria. Int J Basic Appl. Vol. 1, pp. 1-5. (2012)

[17] Kudakwashe M, Mohammed Yesuf K.: Application of Binary Logistic Regression in Assessing Risk Factors Affecting the Prevalence of Toxoplasmosis. Am J Appl Math Stat. Vol. 8, pp. 357-63. (2014)

[18] Thurston SW, Liu G, Miller DP, Christiani DC. Modeling lung cancer risk in case-control studies using a new dose metric of smoking. Cancer Epidemiol Biomarkers Prev. Vol. 14, pp. 2296-302. (2005) 